Gut, 1985, 26, 639-641

Case report

\title{
Acute fulminant non-A, non-B hepatitis leading to chronic active hepatitis after treatment with cryoprecipitate
}

\author{
CHRISTINE A LEE, P B A KERNOFF, P KARAYIANNIS, AND H C THOMAS \\ From the Haemophilia Centre and Haemostasis Unit, and Academic Department of Medicine, Royal Free \\ Hospital. London.
}

SUMmaRY This report describes a carrier of haemophilia A who developed fulminant non-A, non-B hepatitis after transfusion with cryoprecipitate. She survived, but developed chronic active hepatitis.

Non-A, non-B (NANB) hepatitis is responsible for $30-40 \%$ of cases of fulminant liver failure. ${ }^{12}$ The survival rate from fulminant NANB hepatitis is only $9-13 \%$ with no progression to chronic hepatitis. $^{3}$ The majority of patients with posttransfusion NANB hepatitis run an asymptomatic course and $40-80 \%$ develop chronic hepatitis. ${ }^{45}$ This report describes a carrier of haemophilia A who received cryoprecipitate after trauma. The patient developed fulminant NANB hepatitis and ultimately progressed to chronic hepatitis.

\section{Case report}

The patient, a known carrier of haemophilia $\mathrm{A}$ with a basal level of $16 \mathrm{U} / \mathrm{dl}$ factor VIII: C, was 52 years old when she slipped and fell heavily on her right knee. Within one hour the knee was swollen and painful and she could only walk with difficulty. After admission to hospital she was treated with 121 donor units of cryoprecipitate over the course of six days. Before treatment, her aspartate transaminase (AST) was $9 \mathrm{IU} / \mathrm{l}$ (upper limit of normal $40 \mathrm{IU} / \mathrm{l})$. Although her acute symptoms subsided, a residual prepatellar swelling caused limitation of knee flexion and one month later, a haematoma was evacuated from the right prepatellar region under cover of a further 80 donor units of cryoprecipitate.

Address for correspondence: Dr C A Lee, Senior Lecturer. Department of Haematology, Queen Mary`s Hospital, Roehampton. London SW15 5PN.

Received for publication 13 July 1984
In accord with our normal clinical practice in this situation, blood samples were obtained for biochemical liver function tests at two weekly intervals after the initial exposure to cryoprecipitate. In the eighth week, the AST became abnormal at 92 IU/l. When seen one week later the patient gave a history of nausea, malaise, and anorexia for the previous five days and recurrent vomiting for two days. She also described dark urine, looseness of stools and shivering attacks. On examination, she was jaundiced and tender in the epigastrium but the liver was not palpable. Investigations showed; AST $1930 \mathrm{IU} / 1$ (normal range 5-40 IU/l), alkaline phosphatase 13 units/l (normal range 35-130 units/ 1), bilirubin $120 \mathrm{mmol} / \mathrm{l}(\mathrm{N} 5-17 \mu \mathrm{mol} / \mathrm{l})$, glucose $6.6 \mathrm{mmol} / \mathrm{l}$ (normal range $3-5 \mathrm{mmol} / \mathrm{l}$ ), platelet count $390 \times 10^{y} / 1$ (normal range 150-450 $\left.\times 10^{y} / 1\right)$ and prothrombin time 20 seconds control $12 \mathrm{sec}-$ onds (International Normalised Ratio [INR] 1.7) (Figure). Subsequently, serological tests for viral hepatitis were found to be negative. These included IgM antibody to hepatitis A virus, hepatitis B surface antigen ( $\mathrm{HBsAg}$ ), hepatitis B surface and core antibody ( $\mathrm{HBsAb}, \mathrm{HBcAb}$ ) and IgM and IgG antibody to Epstein Barr virus (EBV). Cytomegalovirus (CMV) IgG was less than 1 in 8 . A diagnosis of post-transfusion acute NANB hepatitis was made. This was supported by finding evidence of NANB hepatitis associated antigen in the serum on three occasions using a recently reported RAI antigen/antibody system. ${ }^{6}$

Six days after admission to hospital the patient 


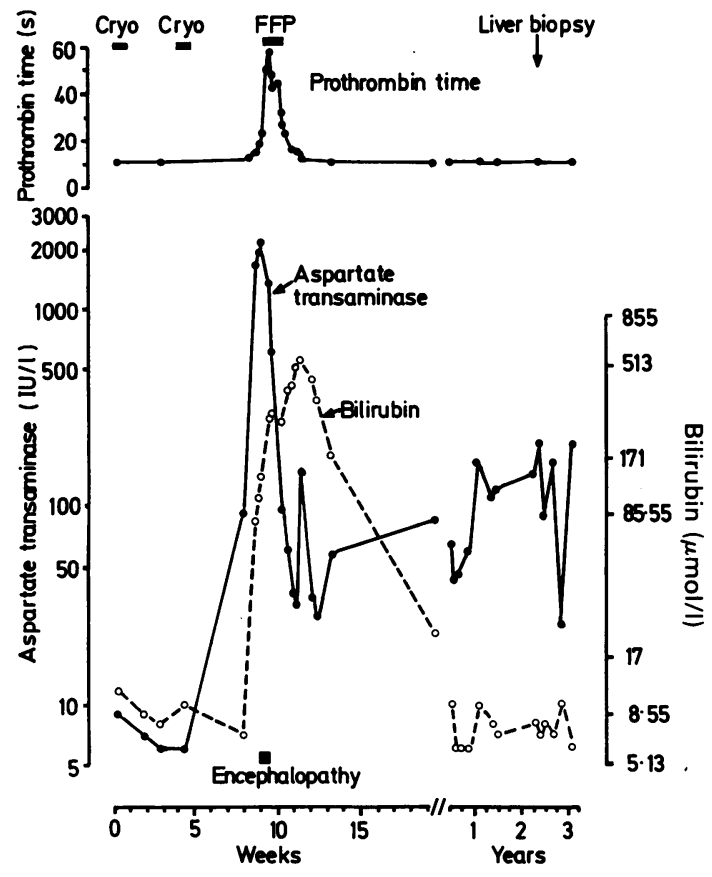

Figure Changes in liver function tests and their relationship to treatment and clinical events.

became confused and disorientated in time and space. The EEG showed sparse alpha components which were replaced by slower components in the theta range and these changes were considered compatible with hepatic encephalopathy. Treatment with fresh frozen plasma over the previous three days had prevented deterioration of the prothrombin time beyond 59 seconds, control 12 seconds (INR 5.0). Treatment with an antiencephalopathy regimen including lactulose, neomycin, potassium, and intravenous glucose was started. Four days later there was a dramatic improvement in the mental state of the patient who was now orientated in time and space. The AST had fallen to $600 \mathrm{IU} / \mathrm{l}$.

The patient continued to improve over the next two weeks. She was discharged from hospital one month after admission when the liver function tests showed an AST of $28 \mathrm{IU} / \mathrm{l}$, alkaline phosphatase 7 units/l, bilirubin $171 \mu \mathrm{mol} / \mathrm{l}$, and a normal prothrombin time.

For two years following the acute illness, the patient was seen regularly as an outpatient and complained of malaise, tiredness, and epigastric discomfort.

A liver biopsy was carried out because her liver function tests were persistently abnormal. This was carried out under cover of 1.deamino.8.D.arginine vasopressin (DDAVP) which raised her plasma VIII: C level from 40-100 U/dl immediately before the biopsy. ${ }^{7}$ A further two injections of DDAVP and only 10 donor units of cryoprecipitate were required to maintain the level above $50 \mathrm{U} / \mathrm{dl}$ for 72 hours.

Hepatic histology showed mild chronic active hepatitis with several histological features suggestive of NANB virus infection: infiltration of the liver sinusoids by mononuclear cells, acidophilic body formation and 'rhomboid' acidophilic change of hepatocytes. ${ }^{8}{ }^{9}$

In view of the minimal piecemeal necrosis no treatment was considered indicated. Although the patient continues to experience intermittent malaise, there are no abnormal clinical signs. The AST three years after exposure to cryoprecipitate was $197 \mathrm{IU} / \mathrm{l}$.

\section{Discussion}

It has been stated that patients with fulminant hepatitis rarely, if ever, develop chronic liver disease. $^{3}$ The patient reported illustrates survival from acute parenterally transmitted fulminant NANB hepatitis with progression to chronic active hepatitis.

The patient was infused a total of 210 donor units of cryoprecipitate on two separate occasions, eight weeks and four weeks, respectively, before onset of hepatitis. She had only once previously been treated with 50 donor units of cryoprecipitate to cover surgical decompression and exploration of the radial nerve for right tennis elbow. In a prospective study of postcardiac surgery patients in America, the incidence of NANB hepatitis was $4 \cdot 3 / 1000$ volunteer donor blood units transfused. ${ }^{10}$ In a more recent study in Britain in post cardiac surgery patients, the incidence of NANB hepatitis was $3 \cdot 3 / 1000$ volunteer donor blood units transfused. ${ }^{11}$ It seems probable that the incidence of NANB hepatitis after infusion of cryoprecipitate is similar. Thus, although the risk of transmitting NANB hepatitis with cryoprecipitate is lower than that associated with large donor pool factor VIII concentrates, ${ }^{12}$ the risk may become significant when large doses are used and the resulting NANB hepatitis may run a severe, protracted course.

A liver biopsy was performed two years after the original exposure to cryoprecipitate and it was to limit further exposure to blood products that the biopsy was covered with DDAVP. ${ }^{7}$ This agent raised the baseline factor VIII: C level from 40 to $100 \mathrm{U} / \mathrm{dl}$ and thus it was possible to maintain an adequate level of factor VIII: C for 72 hours with 
the use of only ten donor units of cryoprecipitate. During the two years after the acute hepatitis the baseline factor VIII: C level had increased spontaneously from $16 \mathrm{U} / \mathrm{dl}$ reflecting the progression to chronic hepatitis. ${ }^{13}$

Patients with post-transfusion NANB hepatitis, including those with chronic active hepatitis, usually show improvement in abnormal serum biochemical values over a period of 1-3 years. ${ }^{4}$ Thus chronic active hepatitis as a sequela of acute NANB hepatitis may have a better prognosis than chronic active hepatitis of other causes. This patient is symtomatic with abnormal serum biochemical values three years after the acute illness and has developed chronic hepatitis, but her long term prognosis is uncertain.

This work was supported by Action Research and the MRC.

\section{References}

1 Gimson AES, White YS, Eddleston ALWF and Williams F. Clinical and prognostic differences in fulminant hepatitis type A, B, and non-A, non-B. Gut 1983; 24: 1194-8.

2 Acute Hepatic Failure Study Group. Aetiology and prognosis in fulminant hepatitis. [Abstract] Gastroenterology 1979; 7: 33A.

3 Karvountzis GG, Redeker AG and Peters RL. Longterm, follow-up studies on patients surviving fulminant viral hepatitis. Gastroenterology 1974; 67: 870-7.

4 Berman M, Alter HJ, Ishak KG, Purcell RH, Jones
EA. The chronic sequelae of non-A, non-B hepatitis. Ann Intern Med 1979; 91: 1-5.

5 Bamber M, Murray A, Arborough BAM, et al. Short incubation non-A, non-B hepatitis transmitted by factor VIII concentrates in patients with congenital coagulation disorders. Gut 1981; 22: 854-9.

6 Luo KX, Karayiannis P, MacDonald Burns D, Bamber M, Kernoff PBA, Thomas HC. Prevalence of a non-A, non-B associated antigen/antibody system detected by radioimmunoassay in acute and chronic liver disease. J Med Virol 1983; 12: 253-65.

7 Mannucci PM, Ruggeri ZM, Pareti FI, Capitanio A. 1.Deamino.8.D.arginine Vasopressin: A new pharmacological approach to the management of haemophilia and von Williebrand's disease. Lancet 1977; 1: 869-72.

8 Bamber M, Murray AK, Weller IVD, Morelli A, Scheuer PJ, Thomas HC, Sherlock S. Clinical and histological features of a group of patients with sporadic non-A, non-B hepatitis. J Clin Pathol 1981; 34: $1175-80$.

9 Dienes HP, Popper H, Arnold W, Lobeck H. Histologic observations in human hepatitis non-A, non-B. Hepatology 1982; 2: 562-71.

10 Alter HJ, Purcell RH, Holland PV, Feinstone SM, Morrow AG, Moritsugu Y. Clinical and serological analysis of transfusion-associated hepatitis. Lancet 1975; 2: 838-41.

11 Collins JD, Bassendine MF, Codd AA, Collins A, Ferner RE and James OFW. Prospective study of posttransfusion hepatitis after cardiac surgery in a British centre. Br Med J 1983; 287: 1422-4.

12 Kernoff PBA, Lee CA, Karayiannis $\mathrm{P}$ and Thomas HC. High risk of non-A, non-B hepatitis after a first exposure to volunteer or commercial clotting factor concentrates: effects of pooled human immunoglobulin. Br J Haematol [In press].

13 Lechner K, Niessner H, Thaler E. Coagulation abnormalities in liver disease. Semin Thromb Hemostas 1977; 4: 140-156. 